\title{
A method for producing avoidance behavior in the turtle
}

\author{
Allen M. Granda, Yoiehi Matsumiya and Charles E. Stirling \\ WALTER REED ARMY INSTITUTE OF RESEARCH
}

\begin{abstract}
Abstraet
A method for determining sensory thresholds in turtles is described using an aversive behavioral paradigm. Relatively large stimulus intensity effects on both latency and amplitude of the response are demonstrated.
\end{abstract}

\section{Introduetion}

The systematic analysis of any animal's behavior presupposes adequate control over the responses under investigation and in animals such as turtles, the behavioral repertoire is limited enough to be of serious concern. Food, often used to control behavior in other animals is less than satisfactory here, for turtles in general eat irregularly, satiate quickly, and so often preclude extended observations. The activity that turtles do very quickly and very well is to withdraw into their shells; this is especially true of head retraction. This response was used as an indicator in an aversive situation with shock as a reinforcer. The technique, developed primarily for measuring visual thresholds, permitted a long stable test series under dark-adapted conditions, where the state of adaptation could be preserved by discrete trials spaced by intervals of darkness. The method would appear to be promising for investigation of other sensory modalities such as audition and touch.

\section{Method}

Two adult female turtles, Pseudemys scripta elegans, of 8-10 in carapace length served as Ss. The animals were housed in large tanks where they were fed horsemeat each day until satiated. Both home-tank and experimental chamber were maintained between $25^{\circ} \mathrm{C}$ and $30^{\circ} \mathrm{C}$ at all times. Before training, the Ss were anesthetized with $2 \mathrm{cc} / \mathrm{kg}$ body weight $30 \%$ sol tricaine methane sulfonate (Sandoz MS 222), and two small holes were drilled in the jaw bone to accomodate size 2-56 stainless steel screws. The screws served for attachment of the response line and as convenient terminals for the administration of shock. No interference with normal behavior was observed in any of the animals because of this procedure.

The $\mathrm{S}$ was tied to the platform in the animal chamber by means of elastic bands (cf. Fig. 1). A sliding cover on the box shielded the animal from all extraneous light except that delivered by the stimulus system. A piece of nylon fishing line, attached to the screws in the animal's lower jaw and passing through the cage to a spring mounted outside, afforded a pulling force on the head of $190 \mathrm{gms}$. The spring was mounted in conjunction with a microswitch in a wheel and so could indicate whenever the applied force was overcome by the animal's

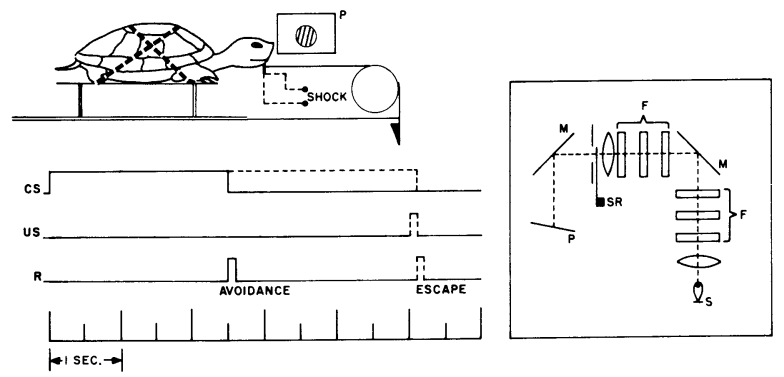

Fig. 1. Schema of animal chamber and stimulus system. Experimental paradigm shown for both avoidance and escape responses.

response, i.e., a counterforce greater than 190 gms. In addition, the extent of the head displacement was measured by the voltage drop across a potentiometer whose value was set by the rotation of the wheel's shaft. The apparatus thus permitted both response latency and intensity measures to be taken.

Light for the stimulus was taken from a tungsten ribbon-filament lamp powered from a regulated source at $6 \mathrm{vac}$ and $18 \mathrm{amps}$. It was conducted by an appropriate optical system to a translucent plexiglass plate where it formed a circular patch, $2 \mathrm{~cm}$ in diameter. The patch was situated about $7 \mathrm{~cm}$ from the S's left eye, at an angle of $75^{\circ}$ from the midsagittal plane. A vibrationless shutter, electrically operated, was programmed to deliver the stimulus. In addition, motorized filter wheels with mounted Wratten neutral density filters and a red filter were used to control both intensity and color of the light. For the present experiment the luminance of the white test patch with no filters in the light pathway measured $32.6 \mathrm{ft}-\mathrm{L}$, for red light $6.3 \mathrm{ft}-\mathrm{L}$.

$\mathrm{AC}$ shock of about $5 \mathrm{ma}$ in intensity was administered through the screw electrodes from a constant current source. The delivery of shock as well as the presentation of light stimuli were controlled by automatic programming equipment.

\section{Procedure}

At the beginning of each session, the animal was fixed to the platform by elastic bands and shock electrodes attached to the screws in its jaw. The nylon line was then fixed in place and the animal left in the dark for 30-45 min. to both stablize adaptation in the eye and accustom the animal to the experimental environment.

For each trial the S's head was extended to a starting point by pulling on the nylon line. Each animal had a critical optimum distance at which it was content to have its head extended, about $3 \mathrm{~cm}$ from its withdrawn position. This position was carefully noted and consti- 


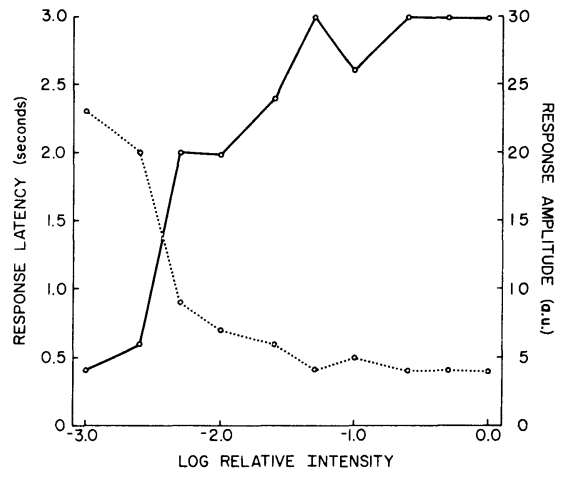

Fig. 2. Latency and response amplitude functions of stimulus intensity. Each point is the mean of 4 determinations from one $S$. Arbitrary units (a. u.) for response amplitude may be read in $\mathrm{mV}$ when multiplied by a factor of 10 .

tuted a zero point from which measures of response amplitude were made. The CS, a particular intensity level of light, was then turned on and followed in $5 \mathrm{sec}$. by the onset of shock.

During acquisition training the S e s c a ped the shock by withdrawing its head. This response terminated the shock and the stimulus light. With more experience, the $\mathrm{S}$ managed to avoid the shock by responding appropriately before the end of $5 \mathrm{sec}$. (cf. Fig. 1). The trials were separated by either 2 or $2.5 \mathrm{~min}$. Daily sessions of 20 trials were given until a criterion of better than $85 \%$ successful avoidance over three sessions was attained for the brightest white light available. Thereafter neutral density filters were introduced at 0.3 and $0.4 \mathrm{log}$ unit steps together with a red filter until the $\mathrm{S}$ again achieved criterion. The addition of neutral density filters was continued until the light intensity was reduced a hundredfold, a value still well above threshold for both Ss. At this point testing began. Frequent control trials, where the light stimulus was occluded, were distributed throughout the sessions.

During actual testing both ascending and descending trials were used; all trials were run without shock, the light being turned off at the end of $5 \mathrm{sec}$. if the S did not respond. The intertrial intervals were the same as in the previous training sessions. To counter the possible effects of this extinction procedure, each daily session began with six training trials paired with shock trials at supra-threshold intensity values.

At the end of testing, extinction trials were run for 10 consecutive sessions. All conditions were the same except that no training trials were held and only one CS intensity was used, $2.0 \mathrm{log}$ units below the maximum luminance of the red filter.

\section{Results}

Use of shock as the UCS always resulted in a headresponse latency of 0.3 to $0.4 \mathrm{sec}$. In the early training trials, the conditioned response was a retraction of all body parts, but the CR gradually became localized to the area at which shock was administered, viz. the head.
The CR also became slightly longer in latency for even the most intense stimuli.

The number of sessions to criterion varied between 15 and 20 for both Ss, i.e., 150-200 trials. During the period in which the intensity of the light was reduced a hundredfold, both Ss never showed less than $60 \%$ correct for any one session, and usually achieved criterion again within two to three sessions.

In the beginning, during testing, both ascending and descending series were used. The ascending trial responses were not very satisfactory, for while the Ss might not respond at very dim lights presumably below threshold, they tended not to react to stimuli usually responded to, even when very bright. The descending series, on the other hand, was much better, varying over a latency range of $2 \mathrm{sec}$. Only rarely did latency approach the $5 \mathrm{sec}$. interval set in the experiment no matter how dim the light stimulus. The relationship between latency and stimulus intensity for descending trials are also plotted. Both relationships are almost monotonic functions of stimulus intensity, becoming asymptotic at higher intensities of light. A similar function was obtained for the second $\mathrm{S}$.

Extinction of responses to light was extremely difficult to obtain; the Ss showed a high resistance to extinction extending beyond several hundred trials.

\section{Diseussion}

That the turtle is capable of avoidance learning is supported by the acquisition and form of appropriate avoidance responses. Of particular interest, however, in animals that have reached criterion, are the response characteristics of latency and amplitude of response. Both of these measures are functions of CS intensity and show rather large effects for a hundredfold stimulus change. Grice \& Hunter (1964) have suggested that the use of several different CS intensity values, as in the present study, results in larger effects than a series where only one intensity value is employed with each animal. In addition, Kimble's (1961, p. 118-122) point that animals show intensity effects to a greater degree than humans may have a bearing.

The persistance of the CR even after prolonged extinction trials is reminiscent of the results of Solomon \& Wynne (1954) who used very strong shock with dogs in an avoidance situation. In the present study with turtles, the vigor of the UCR coupled with loud hissing, voiding of urine, and thrashing would indicate that the level of shock intensity employed is traumatic to the Ss and perhaps a similar explanation to theirs may be invoked.

The results, while preliminary in scope, appear to indicate the usefulness of this method in the investigation of threshold functions for the turtle.

\section{References}

GRICE, G. R., \& HUNTER, J. J. Stimulus intensity effects depend upon the type of experimental design. Psychol. Rev., 1964, 71: 247-256.

KIMBLE, G. A. Hilgard and Marquis' "Conditioning and learning." New York: Appleton-Century-Crofts, 1961.

SOLOMON, R. L., \& WYNNE, L. C. Traumatic avoidance learning: the principles of anxiety conservation and partial irreversibility. Psychol. Rev., 1954, 61: 353-385. 